\title{
Endocrine disruptors in boiled drinking water carried in plastic containers: a pilot study in Thrissur, Kerala, India
}

\author{
T. Geetha ${ }^{1}$ (D)
}

Received: 9 January 2020 / Accepted: 21 October 2021 / Published online: 6 November 2021

(c) The Author(s) 2021

\begin{abstract}
Boiled drinking water is carried by students to schools and colleges in plastic containers. However, the risk associated with drinking water stored in plastic containers is very real especially the question of leachates finding their way into the water stored in these containers. In this pilot study, we identified the most common plastic container used by students to carry water and the factors that govern their choice. Polyethylene terephthalate (PET) was identified as the most favored plastic used to carry water. PET bottles were then subject to treatments that mimic conditions representative of normal consumer usage. The water sample collected was tested for the presence of phthalates, antimony \& titanium, and their content estimated by gas chromatography and atomic absorption spectra. Although phthalates and antimony leach into water from PET bottles their concentration was not high enough to pose a threat to human life. However, the trend of increasing antimony concentration with temperature and time is a cause of concern because of its role as endocrine disruptors. Prolonged and repeated use of PET bottles to carry water, especially warm water may lead to health problems in the community.
\end{abstract}

Keywords Drinking water $\cdot$ PET bottles $\cdot$ Temperature $\cdot$ Antimony $\cdot$ Phthalates $\cdot$ Endocrine disruptors

\section{Introduction}

Water is pivotal to life and safe drinking water an essential requirement for healthy living. In India, majority of the population (about $53 \%$ of households) rely on groundwater resources for their potable water need (Chaudhuri and Roy 2017). The drinking water source is often contaminated (microbial \& otherwise) either due to sewage or polluted water bodies (Subin et. al. 2011, Dhawde et al. 2018 Sharma $P$ 2018) and is responsible for an increased prevalence of various water-borne disease like diarrhea, typhoid fever, hepatitis A, amoebic and bacillary dysentery, and other diarrheal diseases (Fredrick et al. 2015; Boisson et al. 2013).

Boiling water to reduce pathogen load is a scientifically proven method to improve the quality of living (World Health Organization 2004). It is also the method of choice for treating water in small quantities globally, with an estimated 1.2 billion people using it as a means of household water treatment (Brown and Sobsey 2012). Boiling water

T. Geetha

geethamukundant@gmail.com

1 Department of Chemistry, St. Mary's College, Thrissur, Kerala, India for drinking is thus encouraged, and it is a widespread practice in the Southern states especially Kerala (Pushpangadan 2003; John et al. 2004; Kumar Balasundaram et al. 2015). Often boiled drinking water is carried by students to schools and colleges in plastic containers. However, the containers used to carry water rarely conform to the standards required for this purpose. The market is flooded with bottles of various types used to carry water. They range from the most commonly used Polyethylene terephthalate bottles, polycarbonate bottles to those made from steel or glass.

During the last few decades, the use of plastic containers to carry water has increased manifold. This is due to their easy availability, portability, shatter-proof nature, and low cost. The plastic bottles used to carry water are generally made of Polyethylene terephthalate (PET), High-density polyethylene (HDPE), Polycarbonate (PC), Polypropylene (PP), etc. PET is a semi-crystalline polymer belonging to the family of polyesters and is made up of an aromatic ester polymerized into large chains. It is the most widespread polymer used for the manufacture of food contact packaging and films, especially for beverages and drinking water (Bach et al. 2012).It is also one of the most common polymers used to package bottled water due to its lightness, its gas barrier properties, and its possible recyclability. Most PET bottles 
are intended for single-use although some companies recycle up to $25 \%$ of this plastic in the manufacture of new bottles (Guart et al. 2011).

However, the risk associated with drinking water stored in plastic containers is being debated by the scientific community. One of the problems that have drawn the attention of scientists is the question of leachates finding their way into the water stored in these containers. Studies have reported the presence of various chemicals like phthalates (Bošnir et al. 2007) bisphenol A (Amiridou and Voutsa 2011; Cooper et al. 2011) and antimony (Westerhoff et al. 2008) in water from plastic bottles. Concerning health effects, these are often classified as endocrine disruptors because of their ability to interfere with the endocrine system in the body. They are thought to mimic natural hormones, inhibit the action of hormones or alter the normal regulatory functions of the immune, nervous system, or endocrine system (Crisp et al. 1998, Rubin 2011 and Choe et al. 2003).

Long-term exposure to phthalates, alkylphenols, and antimony in humans may lead to teratogenicity, embryotoxicity, mutagenicity, and carcinogenicity (Zarean et al. 2016, Li et al. 2016, Sheikh 2016, Gao 2015). Studies have shown associations between prenatal or postnatal exposure to certain phthalates and reproductive disorders in humans (Sharpe and Irvine 2004). Epidemiologic studies in children show associations between indicators of phthalate exposure at home and risk of asthma and allergies (Jaakkola and Knight 2008).

Research on endocrine disruptors was often focused on packaged drinking water and water treated by the Solar Water Disinfection (SODIS) method. It has been reported that age, storage conditions, frequency of reuse of containers, and temperature may enhance the leaching of endocrine disruptors from the matrix to water (Keresztes et al. 2009; Andra et al. 2011; Andra 2013; Bach et al. 2013; Zaki 2015). In both instances, water remains in the bottle for an extended period of time at different temperatures. However, the pattern of use of plastic water bottles for carrying boiled water is different. In Kerala, water is often boiled before use and transferred to bottles before being cooled completely. Thus, water may be poured into plastic bottles at lukewarm temperature. The problem of leachates from plastic water bottles used for carrying boiled water has not yet been studied. The leachates may be higher as a single container is often used continuously over long periods, thus increasing the probability of leaching from aging plastic. On the other hand, as water stored in contained is consumed daily, the cumulative effect of leaching from matrix to water stored for long periods, as in bottled water is absent, and the quantity of endocrine disruptors per volume of water may be lower. Thus, study on leachates under consumer-relevant conditions is essential. Moreover, the extend of leaching also depends upon the quality of the polymer used for the PET pre-form production (Keresztes et al. 2009). There have been no studies so far on these aspects, especially from India.

In this study, we proposed to identify, through a pilot survey, the percentage of the population that carry boiled water to an educational institution and the most common plastic container used to carry water. The factors that govern their choice of the bottle will be identified through questionnaires. The identified plastic bottle will be then subject to treatments that mimic conditions representative of normal consumer usage. The treated water samples will be analyzed to identify and estimate various leachates like phthalates and antimony. The effect of temperature and repeated use on leaching from plastic bottles to water will also be studied.

\section{Materials and methods}

\section{Survey}

As a part of this project, a survey was conducted in a leading, centrally located, government aided college in Thrissur, Kerala to identify the percentage of the population that carry boiled water to an educational institution and the most common plastic container used by students to carry water. As the college is located in the heart of the city and is well connected to all parts of the district through public transport, it attracts students from different parts of Thrissur district. As the education is subsidized by the government, it is accessible to students from all strata of society. Of the 42 classes in the institution, students of 14 classes were randomly selected for the survey. All the students present on the day participated in the survey, and the following information was collected personally.

- Did they routinely carry bottled water from home for use in the institution?

- Nature of bottle used to carry water-Plastic/glass/steel, etc.

- If plastic bottle-Nature of the plastic bottle used to carry water-PET/PC/any other type of plastic, etc. - recycle code of the bottle was noted.

- The reason why they chose the water bottle.

- Was the water boiled/ filtered/ untreated?

- If boiled- when was the water boiled-previous evening/ morning of the same day

- Was the water allowed to cool completely before being poured into the plastic bottle?

- How often was the bottle replaced? Reason for replacement.

The data collected was recorded and later analyzed by using SPSS software. From this data, the water bottle used most often, factors that govern the choice of bottle, 
probability of warm water being carried in the bottle, and the average period of use were determined.

\section{Sampling}

The most commonly used plastic containers used to carry water were identified and purchased from the local market. 24 bottles were purchased in all. The bottles were cleaned thoroughly by repeated washings. All the bottles were first washed with tap water and then cleaned with soap solution. To eliminate any contamination, the bottles were washed again with tap water and later rinsed thrice with double distilled water.

The study was designed to minimize the risk of background contamination and for this purpose, only glass container and equipment's was used to collect and store distilled water. All the glassware used in the study were cleaned thoroughly and washed repeatedly with double distilled water to minimize contamination. To study the effect of temperature on leaching from plastic bottles, double distilled water of different temperatures was filled in these containers. Based on the survey conducted, the temperature selected for the study was $30,45,60$, and $75{ }^{\circ} \mathrm{C}$. Double distilled water at these temperatures was poured into the plastic bottles, and samples were collected after $24 \mathrm{~h}$. Thus, the effect of temperature on leaching was studied with four temperature treatments and six replicates for each temperature. Three of these were used for estimation of antimony \& titanium while the remaining three were used for estimation of phthalates.

To study the effect of repeated use on leaching from plastic containers under consumer-relevant conditions, the plastic bottles were washed with double distilled water every day and refilled with double distilled water of the same temperature for two months. Samples were collected at the end of $1,3,7,15,30$, and 60 days, respectively. To minimize the risk of contamination, none of the water samples were filtered. The water sample collected was tested for the presence of phthalates, antimony, and titanium, and their content was estimated by gas chromatography and atomic absorption spectra.

\section{Chemicals and supplies}

All chemicals and reagents used in this study were of analytical grade or better unless otherwise stated. Nitric acid $\left(\mathrm{HNO}_{3}\right)$ used for acidification was purchased from Merck, India. Liquid Solid Extraction (LSE) cartridge (PK30 SUPELCLEAN ENVI-18 500MG/6ML) and Phthalate Esters Mix(Bis(2-ethylhexyl) phthalate-DEHP, benzyl butyl phthalate-BBP, Dibutyl phthalate-DBP, Di-N-Octyl Phthalate-DnOP, Diethyl phthalate- DEP, Dimethyl phthalate-DMP) $2000 \mu \mathrm{g} / \mathrm{mL}$ each component in methanol, was purchased from Sigma Aldrich. Anhydrous Granular
Sodium Sulfate, Methylene Chloride and Methanol were purchased from Merck, India.

\section{Analytical procedure}

\section{Estimation of antimony \& titanium}

In the defined intervals for each temperature condition, half a liter of the sample was measured accurately and acidified with $1 \mathrm{ml}$ of $65 \%$ nitric acid to prevent sedimentation. The sample was then digested and placed on an electrical heater to obtain a concentrated volume of $25 \mathrm{ml}$. This was done to detect the very low trace amounts of the elements. To prevent boiling of sample, the condensation was carried out at a relatively lower temperature over a long period of time. The samples were analyzed in an Inductively Coupled Plasma Atomic Emission Spectrometer (ICP-AES) of the make Thermo Electron IRIS INTREPID II XSP DUO for antimony and titanium. The limit of detection (LOD) was $0.1 \mu \mathrm{gL}^{-1}$ for antimony and $0.01 \mu \mathrm{g} \mathrm{L}^{-1}$ titanium. The limit of detection for antimony in some of the previously published studies was lower, of the order of nanogram per liter (Shotyk et al 2006; Keresztes et al. 2009; Filella 2020) but studies with higher detection limits were also reported (Westerhoff et al. 2008; Carneado et al. 2015). As the maximum acceptable concentration of antimony in water is in the order of microgram per liter (WHO guidelines), a limit of detection of $0.1 \mu \mathrm{gL}^{-1}$ for antimony is acceptable for the purpose of this study.

\section{Estimation of phthalates}

Estimation of phthalates in the sample was determined as per EPA method 506 (Munch 1995) and analyzed using gas chromatography. Compounds were separated using a DB1 capillary column $(30 \mathrm{mlength} \times 0.25 \mathrm{~mm}$ I.D., $0.25-\mathrm{mm}$ film thickness). The compounds were separated using the following oven program. The column temperature was initially set at $60{ }^{\circ} \mathrm{C}$ for $1.0 \mathrm{~min}$, then increased at a rate of $6{ }^{\circ} \mathrm{C} / \mathrm{min}$ up to $260{ }^{\circ} \mathrm{C}$, which was then maintained for $10 \mathrm{~min}$. Helium was used as carrier gas (99.99\% purity). The temperature at the injector and the detector was $295^{\circ} \mathrm{C}$. Quantification was done by using the external calibration method with 5 different standards prepared from the original multi-component stock solution showing linear regression correlation $R^{2}>0.98$ for all target analytes. The analytes in the sample were identified by comparing the retention times of the peaks in the sample chromatogram with those of the peaks in standard chromatograms. The analyte concentration corresponding to the sample blank value plus three times the standard deviation gives the limit of detection. The detection limit for DEHP, DBP \& DEP was 0.06, 0.05, and $0.03 \mu \mathrm{gL}^{-1}$. Recovery study for phthalates was done at 
three concentration levels $\left(0.1,0.2\right.$, and $\left.0.4 \mu \mathrm{g} \mathrm{L}^{-1}\right)$. The recoveries were in the range of $79-91 \%$ for DEHP, $78-89 \%$ for DBP, and $71-87 \%$ for DEP.

\section{Results}

\section{Survey}

A survey of 446 students (age varying from 18 to 20) was carried out in January when the days are sunny and the average temperature varies from 23 to $27^{\circ} \mathrm{C}$. Of the total number of students who participated in this survey, $63 \%$ were found to carry water to the educational institution in bottles. The majority of the participants (82\%) carried boiled water while the remaining participants carried either filtered or untreated water in their bottles. Among those who carried water to the institution, almost all the students preferred to use plastic bottles. The use of glass bottles or other materials like steel was not reported.

Of those who used plastic bottles, PET bottles (recycle code \#1) were the most common. $86 \%$ of students used PET bottles to carry water. Around 6\% of students used Polypropylene bottles (recycle code \# 5) and very few students, less than $0.5 \%$ use polycarbonate bottles (recycle code \#7). Based on the above survey, it was decided to restrict the study to PET bottles.

The majority of the students (72\%) reported low cost and portability as the deciding factor in their choice of bottles. This can be borne out by the fact that a large no. of those who used PET bottles used old soft drink bottles to carry water. Of those who carry boiled water to the educational institution, only $20 \%$ of students used water boiled on the previous day. The rest reported transferring warm water to the bottles on the same day as it was boiled. Hence, it can be concluded that the probability of students carrying warm water in plastic (especially PET) bottles to an educational institution is high. $70 \%$ of students reported that they replaced a bottle only when it showed visible signs of deformation.

\section{Concentration of titanium and antimony}

On analysis of the sample, titanium was not identified from any of the samples. PET bottles are synthesized either by using antimony or titanium as a catalyst. It is possible that all the bottles selected for the study may have been manufactured using antimony as a catalyst. When the samples were analyzed for antimony it was observed that antimony content in the sample increased with an increase in temperature of the sample. It was also found to increase with time.

Initially, the antimony content in samples on day one was below the level of detection for all temperatures i.e.,
$30,45,60$, and $75{ }^{\circ} \mathrm{C}$. The values continued to be below the level of detection for all samples on the seventh day. When the samples were analyzed on the 14th day, the concentration of antimony in water poured at 30,45 , and $60{ }^{\circ} \mathrm{C}$ was lower than the limit of detection. For samples in which water was poured at $75{ }^{\circ} \mathrm{C}$, on the 14 th day $5 \mu \mathrm{g} \mathrm{L}-1$ of antimony was recorded in the sample. This value was well within the European Union drinking water standards for antimony $\left(5 \mu \mathrm{g} \mathrm{L}^{-1}\right)$.

When the samples were analyzed after 30 days, samples drawn from bottles in which water was poured at 30 and $45{ }^{\circ} \mathrm{C}$ did not have antimony above the level of detection. In the case of samples drawn from bottles in which water was poured at $60{ }^{\circ} \mathrm{C}$, the value recorded was $5 \mu \mathrm{g} \mathrm{L}^{-1}$. This is well within the European Union drinking water standards for antimony. For samples drawn from the bottle in which the water was poured at $75^{\circ} \mathrm{C}$, the value was $10 \mu \mathrm{g} \mathrm{L}^{-1}$. This value is well within the World Health Organization drinking water standard for antimony $(20 \mu \mathrm{g}$ $\mathrm{L}^{-1}$ ) but it was higher than the European Union and Japan standards.

When the sample was analyzed after 60 days, it was observed that the concentration of antimony in water bottles poured at 30 and $45^{\circ} \mathrm{C}$ was lower than the limits of detection. For samples drawn from bottles in which water was poured at $60{ }^{\circ} \mathrm{C}$, antimony content was $10 \mu \mathrm{g} \mathrm{L} \mathrm{L}^{-1}$ which was higher than European Union and Japan drinking water standard for antimony but lower than WHO standard. For sample poured at $75{ }^{\circ} \mathrm{C}$, the highest value of $20 \mathrm{\mu g} \mathrm{L}^{-1}$ was recorded, which was four times the European Union standard and just within the permitted WHO standards (Fig. 1).

\section{Concentration of phthalates}

Phthalates were not detected in any of the samples analyzed on the first, third, seventh, and fifteenth days. When the samples were analyzed on the 30th day, DEHP, DBP, and DEP were detected in the sample. DEHP concentration in samples poured at 60 and $75^{\circ} \mathrm{C}$ were 0.14 and $0.22 \mu \mathrm{gL}^{-1}$. DEP and DBP were also detected, and their respective concentrations were 0.16 and $0.20 \mu \mathrm{gL}^{-1}$ at $60{ }^{\circ} \mathrm{C}$ and 0.18 and $0.24 \mu \mathrm{gL}^{-1}$ at $75{ }^{\circ} \mathrm{C}$. The value in our study is considerably lower than the values obtained by Bosnir et al. (2007) although their study also did not detect BBP, DnOP, and DMP in water samples. The value of DEHP was more in the range reported by Amiridou and Voutsa (2011).

When the water poured into PET bottles were analyzed after two months, the concentration of DEHP in the sample were 0.18 and $0.24 \mu \mathrm{gL}^{-1}$ at 60 and $75^{\circ} \mathrm{C}$. The value of DEP at 60 and $75^{\circ} \mathrm{C}$ was 0.19 and $0.25 \mu \mathrm{gL}^{-1}$, and for DBP, the values were 0.23 and $0.26 \mu \mathrm{gL}^{-1}$ (Fig. 2). 
Fig. 1 Concentration of antimony in water from PET bottles
Fig. 2 Concentration of DEHP in water from PET bottles
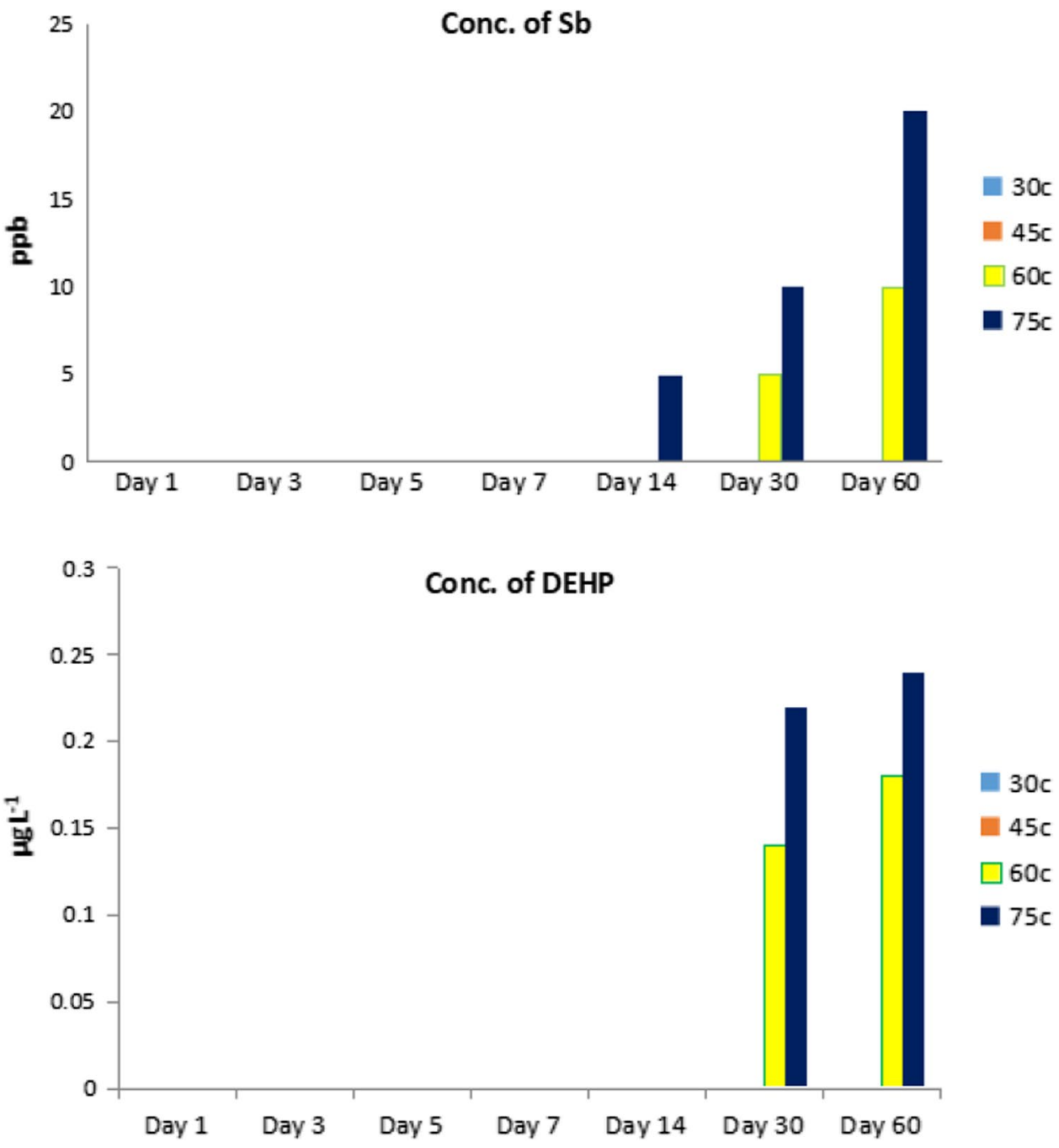

\section{Discussion}

An adequate supply of safe drinking water is one of the major prerequisites for a healthy life. In India, less than 50 percent of the population has access to safely managed drinking water. Water is considered safe for drinking if it is free from toxins, carcinogens, pathogenic microorganisms, and any other factors causing health hazards. Of these microbial contamination is widespread and leads to diseases like diarrhea, which was one of the leading causes of mortality and is responsible for more than 1.6 million deaths worldwide. Treating microbially contaminated water by boiling is a widespread, simple $\&$ effective treatment method. This water is often carried to workplace/educational institutions in PET containers because of its easy availability, portability \& low cost. The use of PET bottles to carry warm/lukewarm water exposes users to possible endocrine disruptors like antimony \& phthalates through leaching from the matrix of the bottle.
As endocrine disturbers, most of the phthalates can cause adverse developmental, metabolic, neurological, immune, and reproductive effects (Abtahi Mehrnoosh et al. 2019). In the absence of other alternative sources of potable water, the adverse effect of trace amounts of phthalates in drinking water needs to be weighed against that of microbially contaminated water that may lead to water-borne diseases. This is especially important as the amount of antimony \& phthalates detected in the water samples were lower than WHO permitted values in this study.

In this study, we have observed that antimony leaching from PET bottles was a function of temperature and time. As the bottles were cleaned thoroughly before use, problems with surface contamination of antimony during the manufacturing process can be ruled out. Moreover, at a higher temperature, an increase in antimony content with time was observed indicating that it was being leached from the matrix of the PET bottle. By the end of the study period, antimony content in water increased fourfold in those bottles where water was poured at $75^{\circ} \mathrm{C}$. This indicates that

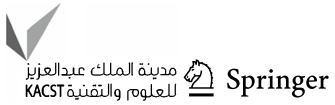


the leaching of antimony from PET bottles increased with the duration of use especially at a higher temperature. The value of our study was higher than the value reported by Keresztes et al. (2009) which varied from 0.2 and $1.6 \mathrm{ng} /$ $\mathrm{mL}$. The higher values found in the current study may be due to greater degradation of PET sample due to reuse frequency (Andra et al. 2011). The study by Carneado et al. (2015) reported values comparable to our values at $60{ }^{\circ} \mathrm{C}$. These conclusions were similar to the conclusion obtained by Aghaee et al. (2014) and Westerhoff et al. (2008), but are at variance from the findings of Rungchang et al. These differences may be attributed to the difference in reactivity of different bottles [Shotyk and Krachler (2007), Reimann et al. (2010).]. Results may also depend on raw material as well as technology used in bottle production. In the case of phthalates, low concentrations of DEHP, DBP, and DEP were detected in the samples poured at an elevated temperature only after 30 days. But even by the end of the study period the amount of DEHP in the water sample was lower than permitted values.

\section{Conclusion}

In this pilot study, PET was identified as the most favored plastic used to carry water to an educational institution. The reason for its popularity is its low cost, transparency, and shatter-proof nature. It is also was used to carry boiled water at varying temperatures to educational institutions. Although phthalates and antimony leach into water from PET bottles, their concentration was not high enough to pose a threat to human life. However, the trend of increasing antimony concentration with temperature and time may be a cause of concern because of its role as endocrine disruptors. As prolonged and repeated use of PET bottles to carry water, especially warm water may be a widespread practice, further research into this aspect is warranted. The effect of prolonged use on the leaching of antimony and phthalates from PET bottles needs to be studied in detail and further studies with a larger sample size, in multiple locations will lead to a better understanding of the problem. In addition, the leaching of phthalates from the matrix of PET bottles may vary with the size and thickness of the bottle used in the study. Thus, it is possible that under different conditions or over time the results may differ.

Funding This work was supported by UGC Grant No. MRP(S)-1375/11-12/KLCA040/UGC-SWRO.

\section{Declarations}

Conflict of Interest The authors have no conflict of interest to declare that are relevant to the content of this article.

Open Access This article is licensed under a Creative Commons Attribution 4.0 International License, which permits use, sharing, adaptation, distribution and reproduction in any medium or format, as long as you give appropriate credit to the original author(s) and the source, provide a link to the Creative Commons licence, and indicate if changes were made. The images or other third party material in this article are included in the article's Creative Commons licence, unless indicated otherwise in a credit line to the material. If material is not included in the article's Creative Commons licence and your intended use is not permitted by statutory regulation or exceeds the permitted use, you will need to obtain permission directly from the copyright holder. To view a copy of this licence, visit http://creativecommons.org/licenses/by/4.0/.

\section{References}

Abtahi M, Dobaradaran S, Torabbeigi M, Jorfi S, Gholamnia R, Koolivand A, Darabi H, Kavousi A, Saeedi R (2019) Health risk of phthalates in water environment: occurrence in water resources, bottled water, and tap water, and burden of disease from exposure through drinking water in Tehran. Iran Environ Res 173:469-479

Aghaee EM, Alimohammadi M, Nabizadeh R, Naseri S, Mahvi AH, Yaghmaeian K, Aslani H, Nazmara S, Mahmoudi B, Ghani M (2014) Effects of storage time and temperature on the antimony and some trace element release from polyethylene terephthalate (PET) into the bottled drinking water. J Environ Health Sci Eng $12: 133$

Amiridou D, Voutsa D (2011) Alkylphenols and phthalates in bottled waters. J Hazard Mater 185(1):281-286

Andra SS (2013) A perspective on human exposures to plastics additives in water-packaging materials. J Water Resource Prot 5(04): 25

Andra SS, Makris KC, Shine JP (2011) Frequency of use controls chemical leaching from drinking-water containers subject to disinfection. Water Res 45(20):6677-6687

Bach C, Dauchy X, Chagnon MC, Etienne S (2012) Chemical compounds and toxicological assessments of drinking water stored in polyethylene terephthalate (PET) bottles: a source of controversy reviewed. Water Res 46(3):571-583

Bach C, Dauchy X, Severin I, Munoz JF, Etienne S, Chagnon MC (2013) Effect of temperature on the release of intentionally and non-intentionally added substances from polyethylene terephthalate (PET) bottles into water: chemical analysis and potential toxicity. Food Chem 139(1):672-680

Boisson S, Stevenson M, Shapiro L, Kumar V, Singh LP, Ward D, Clasen T (2013) Effect of household-based drinking water chlorination on diarrhoea among children under five in Orissa, India: a double-blind randomised placebo-controlled trial. PLoS Med 10(8):e1001497

Bošnir J, Puntarić D, Galić A, Škes I, Dijanić T, Klarić M, Grgić M, Čurković M, Šmit Z (2007) Migration of phthalates from plastic containers into soft drinks and mineral water. Food Technol Biotechnol 45(1):91-95

Brown J, Sobsey MD (2012) Boiling as household water treatment in Cambodia: a longitudinal study of boiling practice and microbiological effectiveness. Am J Trop Med Hyg 87(3):394-398

Carneado S, Hernández-Nataren E, López-Sánchez JF, Sahuquillo A (2015) Migration of antimony from polyethylene terephthalate used in mineral water bottles. Food Chem 166:544-550 
Chaudhuri S, Roy M (2017) Drinking water sources in India: how safe is safe? Curr Sci 10:393-402

Choe SY, Kim SJ, Kim HG, Lee JH, Choi Y, Lee H, Kim Y (2003) Evaluation of estrogenicity of major heavy metals. Sci Total Environ 312(1):15-21

Cooper JE, Kendig EL, Belcher SM (2011) Assessment of bisphenol A released from reusable plastic, aluminium and stainless steel water bottles. Chemosphere 85(6):943-947

Crisp TM, Clegg ED, Cooper RL, Wood WP, Anderson DG, Baetcke KP, Hoffmann JL, Morrow MS, Rodier DJ, Schaeffer JE, Touart LW (1998) Environmental endocrine disruption: an effects assessment and analysis. Environ Health Perspect 106(Suppl 1):11

Dhawde R, Surve N, Macaden R, Wennberg AC, Seifert-Dähnn I, Ghadge A, Birdi T (2018) Physicochemical and bacteriological analysis of water quality in drought prone areas of Pune and Satara districts of Maharashtra. India Environments 5(5):61

Filella M (2020) Antimony and PET bottles: checking facts. Chemosphere 261:127732

Fredrick T, Ponnaiah M, Murhekar MV, Jayaraman Y, David JK, Vadivoo S, Joshua V (2015) Cholera outbreak linked with lack of safe water supply following a tropical cyclone in Pondicherry, India, 2012. J Health Popul Nutr 33(1):31

Gao Y, An T, Ji Y, Li G, Zhao C (2015) Eco-toxicity and human estrogenic exposure risks from $\mathrm{OH}$-initiated photochemical transformation of four phthalates in water: a computational study. Environ Pollut 206:510-517

Guart A, Bono-Blay F, Borrell A, Lacorte S (2011) Migration of plasticizers phthalates, bisphenol A and alkylphenols from plastic containers and evaluation of risk. Food Addit Contam 28(5):676-685

Jaakkola JJ, Knight TL (2008) The role of exposure to phthalates from polyvinyl chloride products in the development of asthma and allergies: a systematic review and meta-analysis. Environ Health Perspec 116(7):845

John TJ, Rajappan K, Arjunan KK (2004) Communicable diseases monitored by disease surveillance in Kottayam district, Kerala state. India Indian J Med Res 120(2):86

Keresztes S, Tatár E, Mihucz VG, Virág I, Záray MC, G, (2009) Leaching of antimony from polyethylene terephthalate (PET) bottles into mineral water. Sci Total Environ 407(16):4731-4735

Kumar Balasundaram P, Libu KG, Jayageetha KP, Retheesh HK (2015) Socio-demographic, clinical and laboratory profile of patients with febrile illness admitted to a tertiary care center in Kerala. Acad Med j India 3(3):88-93

Latini G (2005) Monitoring phthalate exposure in humans. Clin Chim Acta 361(1):20-29

Li B, Xu X, Zhu Y, Cao J, Zhang Y, Huo X (2016) Neonatal phthalate ester exposure induced placental MTs, FATP1 and HFABP mRNA expression in two districts of southeast China. Sci Rep 6:21004

Munch JW (ed) (1995) Determination of Phthalate and Adipate Esters in drinking water by liquid-liquid extraction or liquid-solid extraction and gas chromatography with photoionization detection. National exposure research laboratory, US EPA Cincinnati, Ohio
Pushpangadan K (2003) Drinking water and well-being in India: data envelopment analysis. CDS working papers, no.352. Trivandrum: CDS

Reimann C, Birke M, Filzmoser P (2010) Bottled drinking water: water contamination from bottle materials (glass, hard PET, soft PET), the influence of colour and acidification. Appl Geochem 25(7):1030-1046

Rubin BS (2011) Bisphenol A: an endocrine disruptor with widespread exposure and multiple effects. J Steroid Biochem Mol Biol 127(1):27-34

Rungchang S, Numthuam S, Qiu X, Li Y, Satake T (2013) Diffusion coefficient of antimony leaching from polyethylene terephthalate bottles into beverages. J Food Eng 115(3):322-329

Sharma P (2018) Water quality of River Narmada at Gwari Ghat Jabalpur (MP, India) in Terms of microbial load, drug resistance and potability. J Appl Environ Microbiol 6(1):25-29

Sharpe RM, Irvine DS (2004) How strong is the evidence of a link between environmental chemicals and adverse effects on human reproductive health? BMJ 328(7437):447-451

Sheikh IA (2016) Stereoselectivity and the potential endocrine disrupting activity of di-(2-ethylhexyl) phthalate (DEHP) against human progesterone receptor: a computational perspective. J Appl Toxicol 36(5):741-747

Shotyk W, Krachler M (2007) Contamination of bottled waters with antimony leaching from polyethylene terephthalate (PET) increases upon storage. Environ Sci Technol 41(5):1560-1563

Shotyk W, Krachler M, Chen B (2006) Contamination of Canadian and European bottled waters with antimony from PET containers. J Environ Monit 8(2):288-292

Subin MP, Anitha CT, Sidhimol PD (2011) The study of water quality of Tripunithura, a city suburb of Ernakulam District in Kerala. India Nat Environ Pollut Technol 10(4):583-588

Westerhoff P, Prapaipong P, Shock E, Hillaireau A (2008) Antimony leaching from polyethylene terephthalate (PET) plastic used for bottled drinking water. Water Res 42(3):551-556

World Health Organization (2004) Guidelines for drinking-water quality. WHO, 3rd ed, pp 1-540

Zaki GI (2015) Determination of phthalate esters in Egyptian PETbottled water investigated under different storage conditions. [Master's Dissertation]. Cairo. American university in Cairo

Zarean M, Keikha M, Poursafa P, Khalighinejad P, Amin M, Kelishadi R (2016) A systematic review on the adverse health effects of di-2-ethylhexyl phthalate. Environ Sci Pollut Res 23(24):24642-24693

Publisher's Note Springer Nature remains neutral with regard to jurisdictional claims in published maps and institutional affiliations. 